\title{
Subcutaneous sumatriptan: results of a peculiar, unpublished, comparative, double-blind, randomised, and controlled trial
}

\author{
Peer Tfelt-Hansen
}

Received: 24 January 2011/Accepted: 2 February 2011/Published online: 1 March 2011

(C) The Author(s) 2011. This article is published with open access at Springerlink.com

To the Editor,

Aspirin plus metoclopramide, an antiemetic and prokinetic drug, for acute migraine treatment was introduced by Marcia Wilkinson at The City of London Migraine Clinic [1] and until the advent of sumatriptan, it was in several countries the standard treatment for migraine, see [2]. Sumatriptan, subcutaneous $6 \mathrm{mg}$ and oral $100 \mathrm{mg}$, was introduced in 1991 [3]. Subcutaneous sumatriptan $6 \mathrm{mg}$ resulted in headache relief (HR) (a decrease of headache from moderate or severe to none or mild) in $70-72 \%$ after $1 \mathrm{~h}[4,5]$ and $86 \%$ after $2 \mathrm{~h}$ [4].Oral sumatriptan $100 \mathrm{mg}$ $(56 \% \mathrm{HR})$ was not superior to the oral combination of aspirin 1,000 mg and metoclopramide (ASP + M) $10 \mathrm{mg}$ $(45 \%)$ in the first attack treated, but sumatriptan was better than the combination in the second and third attack [6].

From 1993 to 1994, a randomised, controlled trial (RCT) was performed in France. It had the title: "A randomised, multicentre, double-blind, double-dummy, parallel-group study to compare the efficacy and safety of subcutaneous sumatriptan with oral aspirin plus oral metoclopramide in the acute treatment of migraine" [7].

It was performed in 46 centres in France and showed, as expected, that subcutaneous sumatriptan $6 \mathrm{mg}$ was superior $(p<0.001)$ to efferverscent aspirin $1,000 \mathrm{mg}$ plus metoclopramide $10 \mathrm{mg}$ from 30 to $120 \mathrm{~min}$, see Table 1 . Subcutaneous sumatriptan $6 \mathrm{mg}$ was successful in $84 \%$ of patients at $2 \mathrm{~h}$ and similar results were reported in one pivotal RCT (86\%) on subcutaneous sumatriptan [4]. The headache relief for ASP $+\mathrm{M}$ was $62 \%$ and somewhat

P. Tfelt-Hansen $(\bowtie)$

Department of Neurology, Danish Headache Centre, University of Copenhagen, Glostrup Hospital, Glostrup, Denmark

e-mail: ptha@glo.regionh.dk higher than the $45 \%$ observed in a comparative RCT [6], see above, but in the range of the $56 \%$ headache relief observed in two other RCTs, with highly soluble lysine acetylsalicylate plus metoclopramide [8,9]. The relative high-headache response for ASA + M could be due to the use of effervescent aspirin [7].

The rationale for doing this RCT remains obscure. Why should an injection of an antimigraine drug (the optimal route of administration) be compared with an oral form of another antimigraine drug (a suboptimal form because of slower absorption)? The most likely reason is that this RCT was done solely for registration purposes in France. We don't know whether it was done at the request of the French health authorities. Any way, this RCT, even if based only on the summary, was of good quality and the

Table 1 Headache relief (HR) and therapeutic gain (percentage HR after subcutaneous sumatriptan $6 \mathrm{mg}$ minus percentage HR after effervescent aspirin $1,000 \mathrm{mg}$ plus metoclopramide) for the firsttreated migraine attack

\begin{tabular}{|c|c|c|}
\hline & $\begin{array}{l}\text { Sumatriptan } \\
(n=122)\end{array}$ & $\begin{array}{l}\mathrm{ASP}+\mathrm{M} \\
(n=125)\end{array}$ \\
\hline \multicolumn{3}{|c|}{ Headache relief after $30 \mathrm{~min}$} \\
\hline Yes & $62(50 \%)$ & $31(24 \%)$ \\
\hline No & $62(50 \%)$ & $96(76 \%)$ \\
\hline \multicolumn{3}{|c|}{ Therapeutic gain $26 \%$ (95\% CI 14-37\%) } \\
\hline \multicolumn{3}{|c|}{ Headache relief after $60 \mathrm{~min}$} \\
\hline Yes & $87(71 \%)$ & $57(45 \%)$ \\
\hline No & $35(29 \%)$ & $69(55 \%)$ \\
\hline \multicolumn{3}{|c|}{ Therapeutic gain $26 \%$ (95\% CI 14-38\%) } \\
\hline \multicolumn{3}{|c|}{ Headache relief after $120 \mathrm{~min}$} \\
\hline Yes & $99(84 \%)$ & $79(62 \%)$ \\
\hline No & $19(16 \%)$ & $48(38 \%)$ \\
\hline
\end{tabular}


RCT remains unpublished 17 years later. Publication is an obligation of the clinical investigators [10] and this RCT should have been published many years ago.

\section{Conflict of interest None.}

Open Access This article is distributed under the terms of the Creative Commons Attribution License which permits any use, distribution and reproduction in any medium, provided the original author(s) and source are credited.

\section{References}

1. Wilkinson M (1976) Editorial: the treatment of acute migraine attacks. Headache 15:291-292

2. Olesen J, Aebelholt A, Veilis B (1979) The Copenhagen acute headache clinic: organization, patient material and treatment results. Headache 19:223-227

3. Humhrey PP (2008) The discovery and development of the triptans: a major therapeutic breakthrough. Headache 48:685-687

4. Subcutaneous Sumatriptan International Study Group (1991) Treatment of migraine attacks with sumatriptan. N Engl J Med 325:316-321
5. Cady RK, Wendt JK, Kirchner JR, Sargent JD, Rothrock JF, Skaggs H Jr (1991) Treatment of acute migraine with subcutaneous sumatriptan. JAMA 265:2831-2835

6. The Oral Sumatriptan and Aspirin plus Metoclopramide Comparative Study Group (1992) A study to compare oral sumatriptan with oral aspirin plus oral metoclopramide in the acute treatment of migraine. Eur Neurol 32:177-184

7. Study no.: S2BL99. A randomised, multicentre, double-blind, double-dummy, parallel-group study to compare the efficacy and safety of subcutaneous sumatriptan with oral aspirin plus oral metoclopramide in the acute treatment of migraine. www.gskclinicalstudyregister.com. Assessed October 2010

8. Chabriat H, Joire JE, Danchot J, Grippon P, Bousser MG (1994) Combined oral lysine acetylsalicylate and metoclopramide in the acute treatment of migraine: a multicentre double-blind placebocontrolled study. Cephalalgia 14:297-300

9. Tfelt-Hansen P, Henry P, Mulder K, Scheldewaert RG, Schoenen J, Chazot G (1995) The effectiveness of combined oral lysine acetylsalicylate and metoclopramide compared with oral sumatriptan for migraine. Lancet 346:923-926

10. Ethics Subcommittee of the International Headache Society (1998) Ethical issues in headache research and management. Cephalalgia 18:505-529 